\title{
Method development and validation for the simultaneous determination of fexofenadine hydrochloride and montelukast sodium using rp-hplc
}

\author{
Mounika godavarthi*1 ${ }^{1}$ K.sujana2, A.pramila rani ${ }^{3}$ \\ ${ }^{1,2,3}$ University College of pharmaceutical sciences, Acharya Nagarjuna University, Guntur, \\ Andhra Pradesh, India.
}

\begin{abstract}
This research paper describes simple, specific, accurate and precise reverse phase high pressure liquid chromatographic method for the simultaneous determination of fexofenadine hydrochloride and Montelukast sodium in combined dosage form. The separation was carried out on agilent T.C $-C_{18}$ column(2)4.6 $\times 250 \mathrm{~m} . \mathrm{m}$ with 5 um internal diameter using acetonitrile: TEA $\left(P^{H} 6\right)(80: 20 \mathrm{v} / \mathrm{v})$ as mobile phase at the flow rate of $1 \mathrm{ml} / \mathrm{min}$. RP-HPLC separation of the two drugs was carried out in the absorbance mode at $220 \mathrm{~nm}$. The drugs were resolved satisfactorily with $R t$ values of $3.21 \pm 0.01$ and $6.66 \pm 0.01$ for FEX and MTKT, respectively. The linear regression analysis data for the calibration plots showed good linear relationship with $r^{2}=0.9996$ and 0.9998 for FEX and MTKT, respectively in the concentration range of 12$144 \mu \mathrm{g} / \mathrm{ml}$ for FEX and 1-12 $\mathrm{gg} / \mathrm{ml}$ for MTKT. The method was validated for precision, robustness, specificity and accuracy. The limit of detection and quantitation were 1.41 and $4.29 \mu \mathrm{g} / \mathrm{ml}$, respectively for FEX and 0.02 and $0.06 \mu \mathrm{g} / \mathrm{ml}$, respectively for MTKT. The proposed developed RP-HPLC method can be applied for identification and quantitative determination of FEX and MTKT in bulk drug and drug formulation.
\end{abstract}

Keywords—fexofenadine hydrochloride; montelukast sodium; RP-HPLC; validation.

\section{INTRODUCTION}

Fexofenadine hydrochloride (FEX) (Figure 1) (RS)-2-[4-[1-Hydroxy-4-[4-(hydroxy-diphenyl-methyl)1-piperidyl]butyl]phenyl]-2-methyl-propanoic acid, is used to relieve the allergy symptoms of seasonal allergic rhinitis (hay fever), including runny nose; sneezing; and red, itchy, or watery eyes; or itching of the nose, throat, or roof of the mouth in adults [1]. It is carboxylic acid metabolite of terfenadine, a non-sedating selective histamine H1 receptor antagonist. This drug contains an asymmetric carbon in its chemical structure and is administered clinically or is used as a P-glycoprotein probe as a racemic mixture of $R$ - and $S$-enantiomers [2].

Montelukast sodium (MTKT) (Figure 2) is chemically (S, E)-2-(1-((1-(3-(2-(7-chloroquinolin-2yl)vinyl)phenyl)-3-(2-(2-hydroxypropan-2-yl)phenyl)propylthio)methyl)cyclopropyl)acetic acid [5] is a leukotriene receptor antagonist used in the treatment of chronic asthma and allergic rhinitis [3].

Literature survey reveals that Fexofenadine hydrochloride is estimated individually or in combination with other drugs by UV spectrophotometry [4,5,6], RP-HPLC [7,8,9], HPTLC [10, 11], in biological fluid by RP-HPLC [12,13,14], LC/MS [15], LC/MS/MS [16, 17] and Stability indicating HPLC and TLC method [18].

Similarly for Montelukast sodium, UV spectrophotometry [19,20], spectrofluorometry [21], RP-HPLC [22,23], HPTLC [24,25], plasma HPLC [26,27,28,29], LC/MS [30,31], and stability indicating HPLC methods $[32,33]$ have been reported.

Above literature suggests that no method has been reported for simultaneous determination of FEX and MTKT by RP- HPLC. RP-HPLC method is sensitive, rapid and less time consuming. In RP- HPLC many samples are simultaneously used and solvent requirement is low. So, the present study is designed for the development and validation of simple, precise and accurate RP- HPLC method for the simultaneous determination of FEX and MTKT in tablet formulation. The proposed method is validated as per ICH guidelines [34]. 


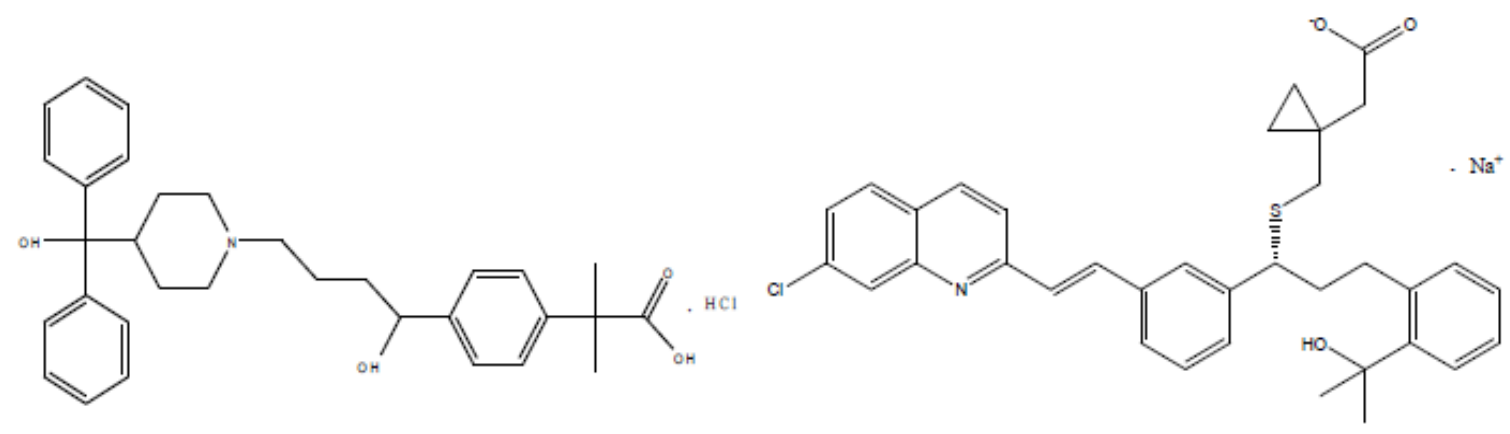

Figure 1. Structure of FEX

Figure 2. Structure of MTKT

\subsection{Materials:}

\section{EXPERIMENTAL}

Working standards of pharmaceutical grade FEX (99.60\%, w/w) and MTKT $(100.0 \%$, w/w) were obtained as gift samples from Unichem Laboratories, Goa, India. Fixed dose combination tablets (MONTAIR FX, B. No. ACF1010, Cipla Ltd. MFG. 05/2011 EXP. 04/2013) containing $120 \mathrm{mg}$ FEX and $10 \mathrm{mg}$ MTKT were purchased from local pharmacy, Hyderabad ,India. All chemicals and reagents of analytical grade were purchased from Merck Chemicals, Mumbai, India.

\subsection{Selection of analytical wavelength:}

Stock solutions of drugs were prepared in methanol separately. UV spectrum of $10 \mu \mathrm{g} \mathrm{mL}-1$ of individual drug was taken. Further, in situ HPLC spectral overlain of FEX and MTKT was taken.

\subsection{Instrumentation and chromatographic conditions:}

\subsubsection{Instruments and Apparatus}

The chromatography was performed on a Agilent RP-HPLC instrument (LC-2010CHT) equipped with DAD detector and LC-solution software, C18 column $(250 \times 4.6 \mathrm{~mm}$ id, $5 \mu \mathrm{m}$ particle size $)$ was used as stationary phase. LC-GC (Axis)AGN 204 PO analytical balance and ultrasonic cleaner (1.5L 50H, PCI Mumbai) were used during the research work.

\subsubsection{Reagents and materials}

Standard samples of MTKT and FEX were obtained from Sun Pharmaceutical Pvt Ltd, (Vadodara, Gujarat). Combination tablet formulation containing Montelukast sodium equivalent to Montelukast $10 \mathrm{mg}$ and fexofenadine hydrochloride $10 \mathrm{mg}$ was procured from local pharmacy. Triple distilled water, methanol, acetronitrile, tri ethyl amine (loba chemicals) used were of HPLC grade.

\subsection{Standard solutions and calibration graphs:}

Accurately weighed MTKT $(10 \mathrm{mg})$ and FEX $(10 \mathrm{mg})$ standards were transferred to a50 ml volumetric flask, dissolved in and diluted up to the mark with methanol to obtain a standard stock solution $(200 \mathrm{mg} / \mathrm{ml}) \mathrm{of}$ MTKT and FEX, each. From the above stock solution, an aliquot $(2.5 \mathrm{ml})$ of the solution was transferred to 50 $\mathrm{ml}$ volumetric flask, and diluted up to the mark with mobile phase to obtain a working standard solution (10 $\mu \mathrm{g} / \mathrm{ml}$ ) of MTKT and FEX, each.

\subsubsection{Preparation of Calibration Curve}

Aliquots of $0.1,0.2,0.4,0.6,0.8,1.0,1.2 \mathrm{ml}$ solutions of montelukast sodium and aliquots of 0.2, 0.4, $0.8,1.2,1.6,2,2.4 \mathrm{ml}$ solutions of fexofenadine hydrochloride were used for mixed working standard solution (equivalent to $1,2,4,6,8,10,12 \mu \mathrm{g} / \mathrm{ml}$ and $12,24,48,72,96,120,144 \mu \mathrm{g} / \mathrm{ml}$ of MTKT and FEX each) were transferred in a series of $10 \mathrm{ml}$ volumetric flasks, and the volume was made up to the mark with mobile phase. An aliquot $(10 \mu \mathrm{l})$ of each solution was injected under the operating chromatographic conditions as described above and responses were recorded. Calibration curves were constructed by plotting the peak areas versus the concentrations, and the regression equations were calculated of fexofenadine hydrochloride and montelukast sodium respectively(fig $3 \&$ fig 4 ). Each response was average of three determinations. 


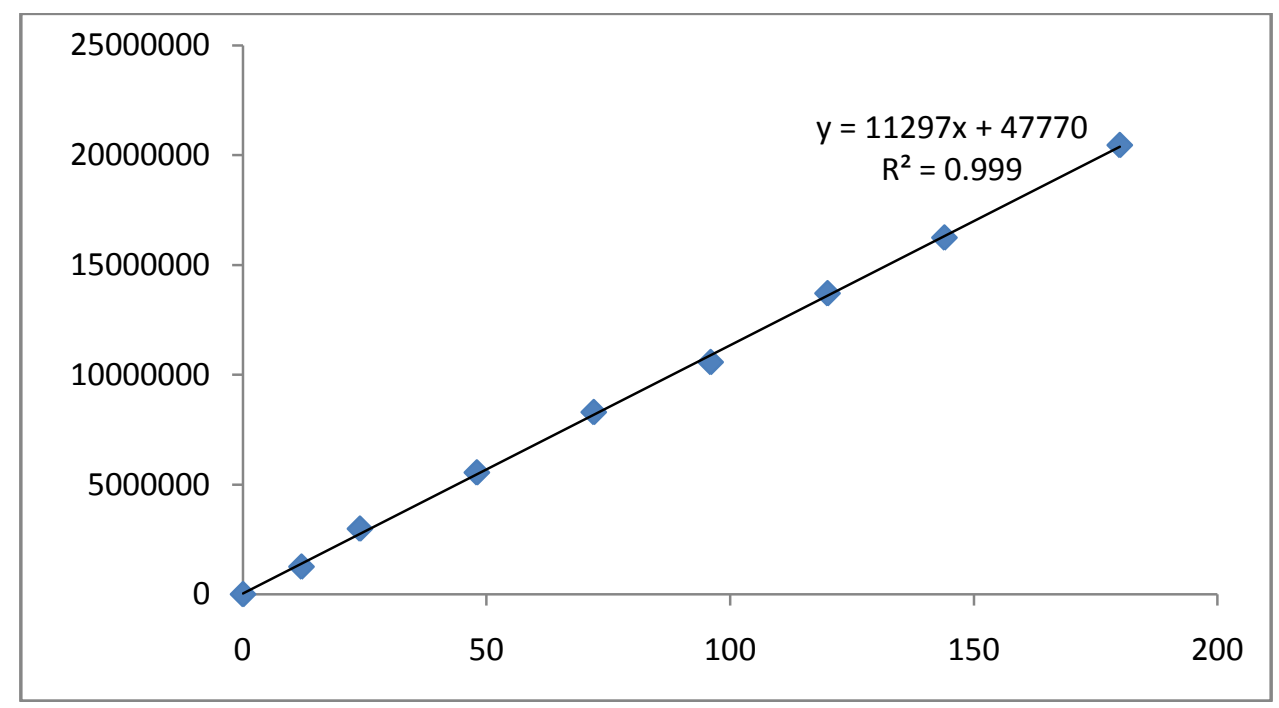

Fig: 3 calibration curve for fexofenadine hydrochloride

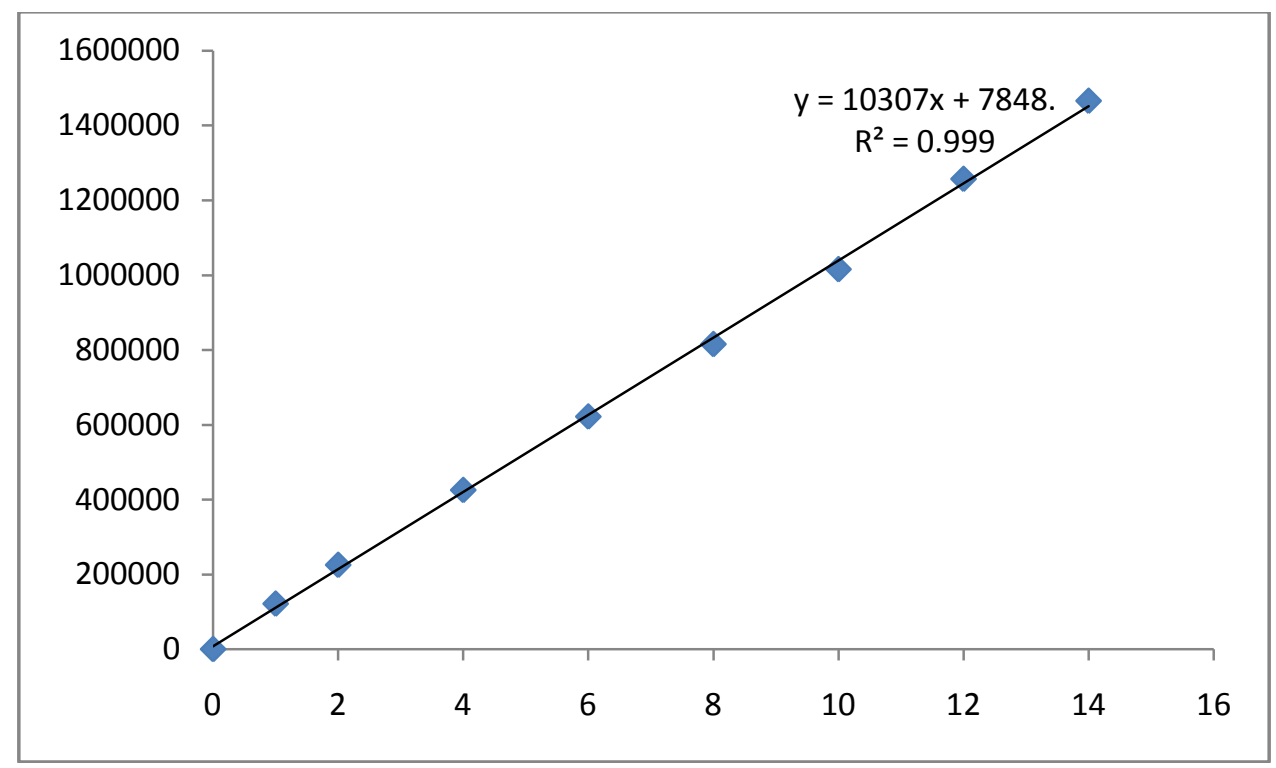

Fig: 4 calibration curve for montelukast sodium

\subsection{Sample preparation:}

To determine the content of FEX and MTKT simultaneously in pharmaceutical dosage form MONTAIR FX (label claim: $120 \mathrm{mg}$ FEX and $10 \mathrm{mg}$ MTKT per tablet, B. No. ACF1010, Cipla Ltd. MFG. 05/2011 EXP. 04/2013). Twenty tablets were weighed and finely powdered. An accurate weight of the powder equivalent to $120 \mathrm{mg}$ of FEX and $10 \mathrm{mg}$ of MTKT was weighed. This was then transferred into FEX was transferred in a $50 \mathrm{ml}$ volumetric flask and methanol $(30 \mathrm{ml})$ was added. The solution was sonicated for $15 \mathrm{~min}$. The flask was allowed to stand for $5 \mathrm{~min}$ at room temperature and the volume was diluted up to the mark with methanol to obtain the sample stock solution of MTKT $(10 \mu \mathrm{g} / \mathrm{ml})$ and FEX $(120 \mu \mathrm{g} / \mathrm{ml})$. The solution was filtered through $0.45 \mu \mathrm{m}-47 \mathrm{~mm}$ membrane filter. An aliquot $(2.5 \mathrm{ml})$ was transferred to a $50 \mathrm{ml}$ volumetric flask and diluted up to the mark with mobile phase used for HPLC, to obtain working sample solution of MTKT (10 $\mu \mathrm{g} / \mathrm{ml})$ and FEX $(120 \mu \mathrm{g} / \mathrm{ml})$. An aliquot of the working test solution was transferred to a $10 \mathrm{ml}$ volumetric flask and diluted up to the mark with mobile phase to obtain the sample solution of MTKT $(6 \mu \mathrm{g} / \mathrm{ml})$ and FEX $(72 \mu \mathrm{g} / \mathrm{ml})$. The peak areas were measured at $220 \mathrm{~nm}$ for FEX and MTKT, respectively. 


\section{METHOD VALIDATION}

The optimized RP-HPLC method was validated with respect to the following Parameters as per the ICH guidelines [37].

\subsection{Precision:}

Precision of the method was determined with the standard and the test sample. The precision of the method was verified by repeatability (intraday) and intermediate precision studies. Repeatability studies were performed by analysis of three different concentrations of working standard of 24, 72, $108 \mu \mathrm{g} / \mathrm{ml}$ for FEX and 2, $6,10 \mu \mathrm{g} / \mathrm{ml}$ for MTKT. Method repeatability was achieved by repeating the same procedure six times on the same day for intra-day precision. The intermediate (interday) precision of the method was checked by performing same procedure on different days under the same experimental conditions. The repeatability of sample application and measurement of peak area were expressed in terms of relative standard deviation (\% R.S.D.) and standard error (S.E.).

An amount of the sample powder equivalent to the label claim of FEX and MTKT was accurately weighed and assayed. System repeatability was determined by six replicate applications and measurement of sample solution at a concentration of $72 \mu \mathrm{g} / \mathrm{ml}$ for FEX and $6 \mu \mathrm{g} / \mathrm{ml}$ for MTKT and the peak areas for real sample were expressed in terms of relative standard deviation (\% R.S.D.).

\subsection{Robustness:}

The robustness was studied by evaluating the effect of small but deliberate variations in the chromatographic conditions. The robustness was studied by analyzing the same samples of MTKT and FEX by deliberate variation in the method parameters. The change in the responses of MTKT and FEX were noted. Robustness of the method was studied by changing the extraction time of MTKT and FEX from tablet dosage forms by $\pm 2 \mathrm{~min}$, composition of mobile phase by $\pm 2 \%$ of organic solvent, flow rate by $\pm 0.2 \mathrm{ml} / \mathrm{min}$ and column oven temperature by $\pm 2^{0} \mathrm{C}$. The parameters used in system suitability test were asymmetry of the chromatographic peak, peak resolution, theoretical plates and capacity factor, as RSD of peak area for replicate injections. The robustness of the method was determined at three different concentration levels of 24, 72, 108 $\mu \mathrm{g} / \mathrm{ml}$ for FEX and 2, 6, $10 \mu \mathrm{g} / \mathrm{ml}$ for MTKT.

3.3. Limit of detection and limit of quantitation:

The detection limit of an individual analytical procedure is the lowest amount of analyte in a sample that can be detected but not necessarily quantitated as an exact value. The quantitation limit of an individual analytical procedure is the lowest amount of analyte in a sample that can be quantitatively determined with suitable precision and accuracy. In order to estimate the limit of detection (LOD) and limit of quantitation $(\mathrm{LOQ})$, the signal to noise ratio $(\mathrm{S} / \mathrm{N})$ of 3 and 10 was determined for six replicate determinations. The limit of detection (LOD) and the limit of quantification (LOQ) of the MTKT and FEX, were calculated using the standard deviation of responses $(\mathrm{N})$ and slopes $(\mathrm{S})$ of respective calibration curves using signal-to-noise ratio.

\subsection{Accuracy:}

$$
\begin{aligned}
& \text { LOD }=3.3 \times \mathrm{N} / \mathrm{S} \\
& \mathrm{LOQ}=10 \times \mathrm{N} / \mathrm{S}
\end{aligned}
$$

Accuracy of the proposed method was carried out by applying the method to pharmaceutical dosage form (FEX and MTKT combination tablets) to which known amounts of FEX and MTKT standard powder corresponding to 80,100 and $120 \%$ of label claim had been added (standard addition method). The absolute recovery was calculated by comparing the peak areas obtained from standard solution of FEX and MTKT with the peak areas of samples of different concentration. Six determinations at each level of concentration were performed and the results obtained were compared with expected results.

\section{RESULTS AND DISCUSSION}

4.1. Selection of analytical wavelength:

UV spectrum of FEX and MTKT showed maximum absorbance at $220 \mathrm{~nm}$ and $344 \mathrm{~nm}$, respectively (Figure5).

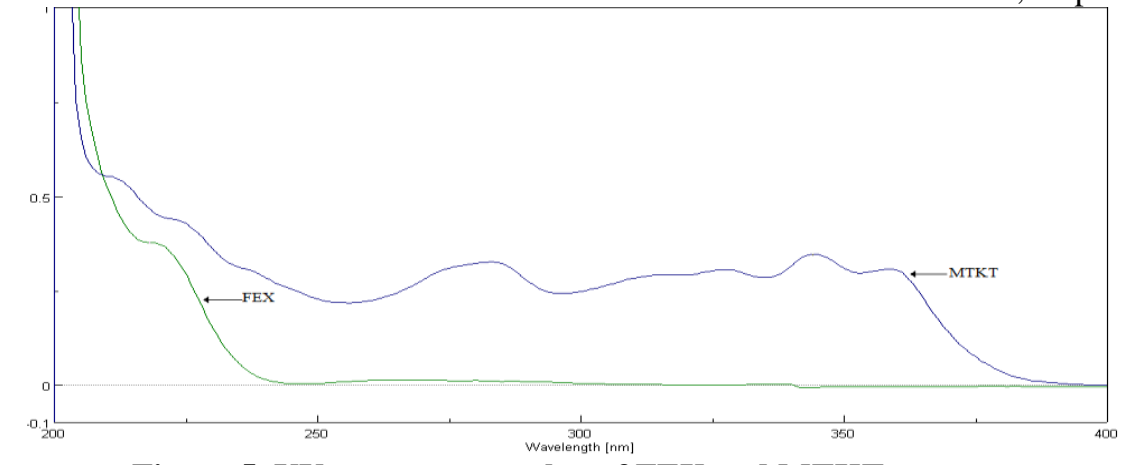

Figure 5. UV spectrum overlay of FEX and MTKT 


\subsection{Optimization of mobile phase:}

Optimization of mobile phase was done with a view to separate FEX and MTKT drugs. Since, initially tested mobile phase, which was composed of Acetonitrile :water(90:10 v/v) showing broad peak shape and complete separation was observed as the $R \mathrm{f}$ of FEX was 0.40 and $R \mathrm{f}$ of MTKT was 0.47 [26]. Several other ratios of the same mobile phase components were tested. Such ratios included acetonitrile: water (85:15), (80:20). However, since these mobile phases did not lead to the aimed result so, mobile phase was changed to acetonitrile:water( $\mathrm{pH} 3)(80: 20 \mathrm{v} / \mathrm{v}),(75: 25 \mathrm{v} / \mathrm{v})$ which was showing void peak and incomplete separation of drugs was observed . However, since these mobile phases did not lead to the aimed result so, mobile phase was changed to acetonitrile : water $(\mathrm{pH} 4.1)(75: 25 \mathrm{v} / \mathrm{v})$ which was showing incomplete separation of drugs .So the mobile phase changed to acetonitile : TEA $(\mathrm{pH} 6)(85: 15 \mathrm{~V} / \mathrm{V}),(82: 18 \mathrm{v} / \mathrm{v})$ has showed good sharp peak but separation is not good. So mobile phase ratio has been changed to acetonitrile : TEA(pH 6) the result showed good separation with $R \mathrm{f}$ of 0.20 and 0.60 for FEX and MTKT, respectively. Finally, a mobile phase with a combination of acetonitrile :TEA(pH 6)(80:20v/v) gave sharp, well-resolved peaks with $R \mathrm{t}$ values of $3.21 \pm 0.01$ and $6.66 \pm 0.01$ for FEX and MTKT, respectively(fig 6). Simultaneous detection of FEX and MTKT was performed at $220 \mathrm{~nm}$ since both compounds are well known to exhibit sufficient ultraviolet absorption at this wavelength.

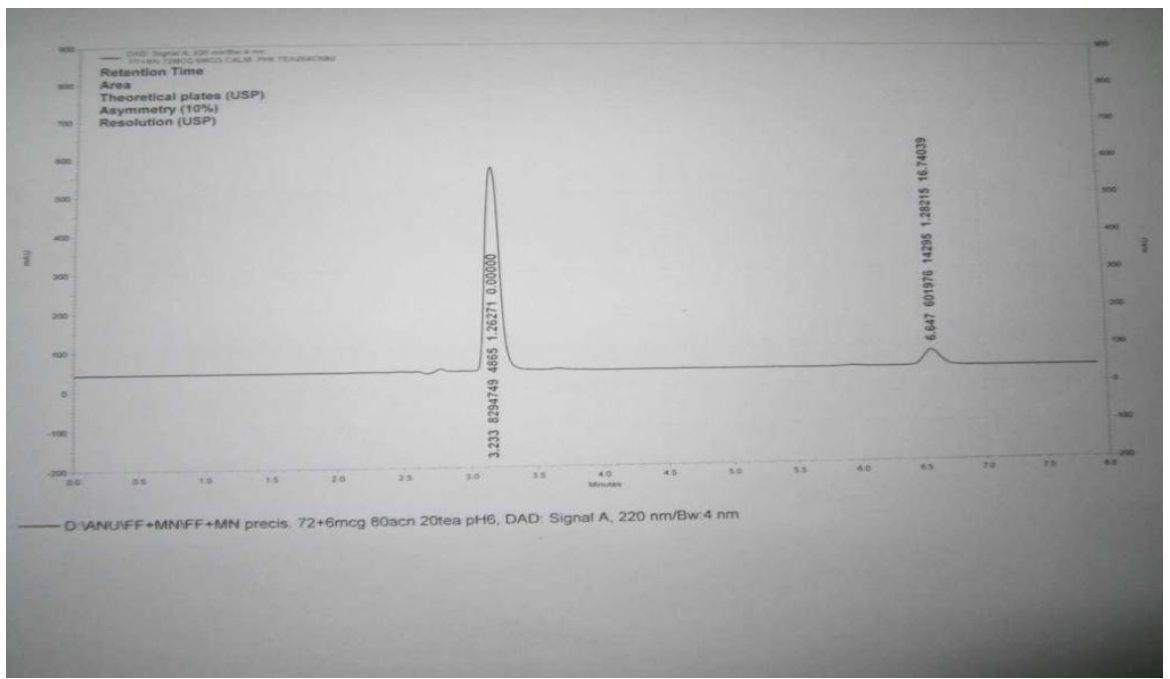

Fig: 6 High performance chromatogram of fexofenadine hydrochloride and motelukast sodium at $220 \mathrm{~nm}$, with retention time of 3.22 and 6.64 min respectively

\subsection{Linearity:}

Linear relationships were observed by plotting drug concentration against peak areas for each compound. FEX and MTKT showed linear response in the concentration range of 12-144 $\mu \mathrm{g} / \mathrm{ml}$ and $1-14 \mu \mathrm{g} / \mathrm{ml}$, respectively. The corresponding linear regression equation was $\mathrm{y}=111297 \mathrm{X}+4770$ and $\mathrm{y}=10307 \mathrm{X}+7849$ with square of correlation coefficient (r2) of 0.9996 and 0.9998 for FEX and MTKT, respectively.

Table 1. Regression analysis data and summary of validation parameter for the proposed method

\begin{tabular}{|l|l|l|}
\hline Parameters & FEX & MTKT \\
\hline Linearity range & $12-144 \mu \mathrm{g} / \mathrm{ml}$ & $1-12 \mu \mathrm{g} / \mathrm{ml}$ \\
\hline Slope & 111297 & 10307 \\
\hline intercept & 47770 & $\mathbf{7 8 4 9}$ \\
\hline Correlation coefficient & $\mathbf{0 . 9 9 9 6}$ & $\mathbf{0 . 9 9 9 8}$ \\
\hline LOD & 1.41 & $\mathbf{0 . 0 2}$ \\
\hline LOQ & 4.29 & $\mathbf{0 . 0 6}$ \\
\hline \% Recovery(accuracy) & $100.2 \pm 0.31$ & $\mathbf{1 0 0 . 1} \pm 0.19$ \\
\hline Repeatability(\% RSD) & $\mathbf{0 . 0 0 2 6}$ & $\mathbf{0 . 0 0 3 1}$ \\
\hline Presicion & & \\
\hline Intra day & 0.27 & 0.29 \\
\hline Inter day & 0.37 & 0.21 \\
\hline
\end{tabular}

$\mathrm{RSD}$ is a relative standard deviation, $\mathrm{n}$ is number of determinations, FEX is fexofenadine hydrochloride,MTKT is montelukast sodium. 
Method development and validation for the simultaneous determination of fexofenadine...

Table 2: System Suitability Test Parameters for Fex and Mtkt for Proposed Method

\begin{tabular}{|l|l|l|}
\hline parameters & FEX & MTK \\
\hline Retention time(mins) & $\mathbf{3 . 2 2}$ & 6.66 \\
\hline Asymmetry factor & 1.26 & $\mathbf{1 . 2 8}$ \\
\hline Theoretical plates & 4865 & $\mathbf{1 4 2 9 5}$ \\
\hline
\end{tabular}

4.4. Precision:

The \% R.S.D. values depicted in TABLE 3 shows that proposed method provides acceptable intra-day and interday variation of FEX and MTKT with respect to working standard.

Table 3. Intra -day and inter d-day precision of fex and mtkt $(n=6)$

\begin{tabular}{|l|l|l|l|l|l|}
\hline Drug & Concentration $(\boldsymbol{\mu g} / \mathrm{ml})$ & \multicolumn{2}{l|}{ Repeatability } & \multicolumn{2}{l|}{ Intermediate precision } \\
\hline & Drug conc & Found conc & \%RSD & Found conc. & \% RSD \\
\hline & 24 & 23.99 & 0.52 & 42.69 & 0.74 \\
\hline FEX & 72 & 72.84 & 0.22 & 72.02 & 0.12 \\
\hline & 108 & 107.46 & 0.09 & 107.67 & 0.26 \\
\hline & 2 & 2.15 & 0.74 & 2.32 & 0.47 \\
\hline MTK & 6 & 6.07 & 0.19 & $\mathbf{6 . 1 5}$ & $\mathbf{0 . 1 1}$ \\
\hline & 10 & 9.65 & $\mathbf{0 . 0 8}$ & $\mathbf{9 . 8 9}$ & $\mathbf{0 . 0 6}$ \\
\hline
\end{tabular}

The repeatability of real sample application and measurement of peak areas were expressed in terms of $\%$ R.S.D. and were found to be 0.61 and 0.26 for FEX and MTKT, respectively.

\subsection{Robustness:}

The standard deviation of the peak areas were calculated for each parameter and the \% R.S.D. was found to be less than $2 \%$. The low values of the \% R.S.D., as shown in TABLE 4 indicated the robustness of the method.

Table 4. Robustness testing of method $(n=6)$

\begin{tabular}{|l|l|l|l|l|}
\hline Parameter & Peak area & \%RSD & MTKT \\
\hline Flow rate $(1.1 \mathrm{ml} / \mathrm{min})$ & FEX & MTKT & FEX & 0.0023 \\
\hline Flow rate $(0.9 \mathrm{ml} / \mathrm{min})$ & $\mathbf{9 4 1 5 4 0 1}$ & $\mathbf{4 6 7 0 3 3}$ & $\mathbf{0 . 0 0 1 9}$ & $\mathbf{0 . 0 0 3 9}$ \\
\hline Wave length $(218 \mathrm{~nm})$ & 11463892 & $\mathbf{5 2 1 2 6 6}$ & $\mathbf{0 . 0 0 2 5}$ & $\mathbf{0 . 0 0 5 1}$ \\
\hline Wave length $(222 \mathrm{~nm})$ & $\mathbf{1 0 3 0 0 6 0 5}$ & $\mathbf{5 2 0 3 0 7}$ & $\mathbf{0 . 0 0 4}$ & $\mathbf{0 . 0 0 7}$ \\
\hline
\end{tabular}

\subsection{Limit of detection and limit of quantitation:}

The signal/noise ratios 3:1 and 10:1 were considered as LOD and LOQ, respectively. The LOD and LOQ were found to be $\mathbf{1 . 4 1 , 4 . 2 9} \mu \mathrm{g} / \mathrm{ml}$ and $\mathbf{0 . 0 2}, \mathbf{0 . 0 6} \mu \mathrm{g} / \mathrm{ml}$ for FEX and MTKT, respectively.

4.7. Accuracy:

As shown from the data in TABLE 5 satisfactory recovery $\%$ in the limit of $98-102 \%$ with small relative standard deviations (\% R.S.D.) obtained at various added concentrations. The results indicate that the method is highly accurate for simultaneous determination of FEX and MTKT.

Table 5. Accuracy studies for the determination of (a) fex and (b) mtkt (n=6) Fex

\begin{tabular}{|l|l|l|l|l|l|l|}
\hline $\begin{array}{l}\text { Amount of drug } \\
\text { formulation }\end{array}$ & $\begin{array}{l}\text { Amount of pure drug } \\
\text { added }\end{array}$ & \%added & $\begin{array}{l}\text { Peak } \\
\text { area }\end{array}$ & $\begin{array}{l}\text { Amount } \\
\text { found }\end{array}$ & \%recovery & \%RDD \\
\hline 8 & 6 & 80 & 1399158 & 6.06 & 101 & 0.003 \\
\hline 8 & 8 & 100 & 1598868 & 8.03 & 100.5 & 0.0045 \\
\hline 8 & 10 & 120 & 1800524 & 10.08 & 100.7 & 0.0068 \\
\hline
\end{tabular}

\begin{tabular}{|l|l|l|l|l|l|l|}
\hline $\begin{array}{l}\text { Amount of } \\
\text { drug } \\
\text { formulation }\end{array}$ & $\begin{array}{l}\text { Amount of } \\
\text { pure drug } \\
\text { added }\end{array}$ & \% added & Peak area & $\begin{array}{l}\text { Amount } \\
\text { found }\end{array}$ & \%recovery & \% RSD \\
\hline 96 & 72 & $\mathbf{8 0}$ & 18563621 & 71.9 & 100.5 & $\mathbf{0 . 0 0 2 1}$ \\
\hline 96 & 96 & 100 & 21132058 & 96.9 & 101.0 & $\mathbf{0 . 0 0 3 6}$ \\
\hline 96 & 120 & 120 & 23936827 & 121.9 & 101.6 & $\mathbf{0 . 0 0 5 4}$ \\
\hline
\end{tabular}




\subsection{Analysis of a marketed pharmaceutical dosage form:}

Using the proposed chromatographic method, assay of FEX and MTKT in their tablets (MONTAIR FX, label claim: $120 \mathrm{mg}$ FEX and $10 \mathrm{mg}$ MTKT per tablet, B. No. ACF1010, Cipla Ltd. MFG. 05/2011 EXP. 04/2013) was carried out. Satisfactory results were obtained for both drugs in a good agreement with the label claim as shown in TABLE 6. The drug content was found to be $101.12 \% \pm 0.98$ (\%R.S.D. of 0.98 ) and $101.51 \% \pm 1.06$ (\%R.S.D. of 1.07) for FEX and MTKT, respectively.

Table 6. Assay results for tablets using the proposed method

\begin{tabular}{|l|l|l|l|l|l|l|}
\hline formulation & \multicolumn{2}{|l|}{ Amount of drug taken } & \multicolumn{2}{l|}{ Amount of drug found } & \multicolumn{2}{|c|}{ \%amount found } \\
\hline Tablets & FEX & MTKT & FEX & MTKT & FEX & MTKT \\
\hline & $96(\mu \mathrm{g} / \mathrm{ml})$ & $8(\mu \mathrm{g} / \mathrm{ml})$ & 97.1 & 8.12 & 101.1 & 101.5 \\
\hline
\end{tabular}

\section{CONCLUSION}

The responses of sample solutions were measured at $220 \mathrm{~nm}$ for quantitation of FEX and MTKT by the proposed methods. The amount of FEX and MTKT present in the sample solutions were determined by fitting the responses into the regression equations of the calibration curve for FEX and MTKT, respectively. The mobile phase consisting of acetonitrile: TEA (tH6) $(80: 20 \mathrm{v} / \mathrm{v})$, at a flow rate of $1.0 \mathrm{ml} / \mathrm{min}$ was found to be satisfactory to obtain good peak symmetry, better reproducibility and repeatability for FEX and MTKT. Quantification was achieved with DAD detector at $220 \mathrm{~nm}$ based on peak area. The retention times were found to be 3.21 and $6.66 \mathrm{~min}$ for FEX and MTKT, respectively (Figure 1).Linear correlation was obtained between peak area and concentration for FEX and MTKT, each, in the range of $12-144 \mu \mathrm{g} / \mathrm{ml}$ and $1-12 \mu \mathrm{g} / \mathrm{ml}$ respectively (Table 1). The method was found to be specific as no significant change in the responses of FEX and MTKT was observed after $24 \mathrm{~h}$. The percent mean recoveries obtained for MTKT and FEX were 100.2 \pm $0.31 \%$ RSD and $100.1 \pm 0.19 \%$ RSD (Table 1), which suggest accuracy of the method. The values of \% RSD for intraday and interday variations were found to be 0.27 and 0.37 for FEX, and 0.29 and 0.21 for MTKT, respectively (Table 1). \% RSD for repeatability was found to be 0.0026 and 0.0031 for FEX and MTKT, respectively. Low RSD values for precision suggest that the method is precise. The LOD and LOQ were found to be 1.41 and $4.29 \mu \mathrm{g} / \mathrm{ml}$ for FEX, 0.02 and $0.6 \mu \mathrm{g} / \mathrm{ml}$ for MTKT, respectively (Table 1), suggest sensitivity of the method. Results of system suitability testing are given in Table 2. The results obtained for FEX and MTKT were comparable with the corresponding labeled claim (Table 6).

\section{REFERENCES}

[1]. Allergic Rhinitis and Chronic Idiopathic Urticaria," Drugs, vol. 59, no. 2, pp. 301-321, 2000.

[2]. D. K. Robbins, M. A. Castles, D. J. Pack, V. O. Bhargava and S. J. Weir, "Dose Proportionality and Comparison of Single and Multiple Dose Pharmacokinetics of Fexofenadine (MDL 16455) and its Enantiomers in Healthy Male Volunteers," Biopharmaceutics and Drug Disposition, vol. 19, no. 7, pp. 455-463, 1998.

[3]. J. O' Neil. Maryadele, "An Encyclopedia of Chemicals, Drugs and Biologicals," The Merck Index, 14th edition, Merck and Co. Inc., Whitehouse station, NJ, pp. 6253, 2006.

[4]. H. E. Claesson and S. E. Dahlen, "Asthma and leukotrienes: antileukotrienes as novel anti-asthmatic drugs," Journal of Internal Medicine, vol. 245, no. 3, pp.205-27, 1999.

[5]. P. V. Polawar, U. D. Shivhare, K. P. Bhusari and V. B. Mathur, "Development and Validation of Spectrophotometric Method of Analysis for Fexofenadine HCl," Research Journal of Pharmacy and Technology, vol. 1 , no. 4, pp. 539-540, 2008.

[6]. B. Narayana and K. Veena, "A New Method for the Spectrophotometric Determination of Fexofenadine Hydrochloride," Indian Journal of Chemical Technology, vol. 17, pp. 386-390, 2010.

[7]. K. S. Kumar, V. Ravichandran, M. K. Mohan Maruga Raja, R. Thyagu and A. Dharamsi, "Spectrophotometric Determination of Fexofenadine Hydrochloride," Indian Journal of Pharmaceutical Sciences, vol. 68, no. 6, pp. 841-842, 2006.

[8]. M. M. Ruben, M. C. Patricia, E. V. Silvana and S. K. Teodoro, "Alternative and Improved Method for the Simultaneous Determination of Fexofenadine and Pseudoephedrine in their Combined Tablet Formulation," Journal of Pharmaceutical and Biomedical Analysis, vol. 45, no. 5, pp. 804-810, 2007.

[9]. T. Radhakrishna and G. Om Reddy, "Simultaneous Determination of Fexofenadine and its Related Compounds by HPLC," Journal of Pharmaceutical and Biomedical Analysis, vol. 29, no. 4, pp. 681-690, 2002.

[10]. S. Karakus, I. Kucukguzel and S. G. Kucukguzel, "Development and Validation of A Rapid RP-HPLC Method for the Determination of Cetirizine or Fexofenadine with Pseudoephedrine in Binary Pharmaceutical Dosage Forms," Journal of Pharmaceutical and Biomedical Analysis, vol. 46, no.2, pp. 295-302, 2008.

[11]. P. Solairaj, A. R. Bhat, G. K. Suvarna, R. Govindarajan, R. Venkatraman, "HPTLC Method for the Estimation of Fexofenadine $\mathrm{HCl}$ in Tablet Dosage Form," Indian drugs, vol. 42, no.7, pp. 424-427, 2005.

[12]. S. N. Meyyanathan, P. A. Shirsode, B. Suresh, "Analysis of Fexofenadine in Pharmaceutical Preparations by High Performance Thin Layer Chromatography,” Indian drugs, vol. 42, no. 4, pp. 248-250, 2005. 
[13]. M. Miura, T. Uno, T. Tateishi and T. Suzuki, "Determination of Fexofenadine Enantiomers in Human Plasma with High-Performance Liquid Chromatography," Journal of Pharmaceutical and Biomedical Analysis, vol. 43, no.2, pp. 741-745, 2007.

[14]. T. Uno, N. Yasui-Furukori, T. Takahata, K. Sugawara and T. Tateishi, "Liquid Chromatographic Determination of Fexofenadine in Human Plasma with Fluorescence Detection," Journal of Pharmaceutical and Biomedical Analysis, vol. 35, no. 4, 937-942, 2004.

[15]. M. S. Arayne, N. S. H. Shehnaz and A. Haider, "RP-HPLC Method for the Quantitative Determination of Fexofenadine Hydrochloride in Coated Tablets and Human Serum," Medicinal Chemistry Research, vol. 20, no. 1, pp. 55-61, 2011.

[16]. W. Naidong, W. Z. Shou, T. Addison, S. Maleki, X. Jiang, "Liquid Chromatography/Tandem Mass Spectrometric Bioanalysis Using Normal Phase Columns with Aqueous Organic Mobile Phases-A Novel Approach of Eliminating Evaporation and Reconstitution Steps in 96-Well SPE," Rapid Communication in Mass Spectrometry, vol. 16, no. 20, pp. 1965-1975, 2002.

[17]. M. Gergov, J. N. Robson, I. Ojanpera", O. P. Heinonen, E. Vuori, "Simultaneous Screening and Quantitation of 18 Antihistamine Drugs in Blood by Liquid Chromatography Ionspray Tandem Mass Spectrometry," Forensic Science International, vol. 121, no. 1, pp. 108-115, 2001.

[18]. I. Fu, E. J. Woolf, B. K. Matuszewski, "Determination of Fexofenadine in Human Plasma Using 96-Well Solid Phase Extraction and HPLC with Tandem Mass Spectrometric Detection," Journal of Pharmaceutical and Biomedical Analysis, vol. 35, no. 4, pp. 837-846, 2004.

[19]. A. R. Breier, N. S. Nudelman, M. Steppe, E. E. S. Schapoval, "Isolation and Structure Elucidation of Photodegradation Products of Fexofenadine," Journal of Pharmaceutical and Biomedical Analysis, vol. 46, no. 2, pp. 250-257, 2008.

[20]. V. Pawar, S. Pai and G. K. Roa, "Development and Validation of UV Spectrophotometric Method for Simultaneous Estimation of Montelukast Sodium and FEXbuterol Hydrochloride in Bulk and Tablet Dosage Formulation," Jordan Journal of Pharmaceutical Sciences, vol. 1, no. 2, pp. 152-157, 2008.

[21]. L. K. Garg, B. R. Kumar, Dr. S. S. Sait, Dr. T. Krishnamurthy, "Determination of Montelukast Sodium in Oral Granules Dosage Forms by A Simple and Accurate UV Spectrophotometric Methods," International Journal of Pharmaceutical Sciences Review and Research, vol. 7, no. 2, Article-012, pp. 69-72, 2011.

[22]. I. Alsarra, N. Y. Khalil, M. Sultan, R. Al-Ashban, F. Belal, "Spectrofluorimetric Determination of Montelukast in Dosage Forms and Spiked Human Plasma," Phaemazie, vol. 60, no. 11, pp. 823-826, 2005

[23]. Atul S. Rathore, L. Sathiyanarayanan, K.R. Mahadik, "Development of Validated HPLC and HPTLC Methods for Simultaneous Determination of Levocetirizine Dihydrochloride and Montelukast Sodium in Bulk Drug and Pharmaceutical Dosage Form," Pharmaceutica Analytica Acta, vol. 1, no. 1, pp. 1-6, 2010.

[24]. T. Radhakrishnaa, A. Narasarajua, M. Ramakrishnab and A. Satyanarayana, "Simultaneous Determination of Montelukast and Loratadine by HPLC and Derivative Spectrophotometric Methods," Journal of Pharmaceutical and Biomedical Analysis, vol. 31, no. 2, pp. 359-368, 2003.

[25]. R.T. Sane, Ajay Menezes, Mandar Mote, Atul Moghe, Gunesh Gundi, "HPTLC Determination of Montelukast Sodium in Bulk Drug and in Pharmaceutical Preparations," Journal of Planar Chromatography, vol. 17, no. 1, pp. 75-78, 2004

[26]. S. Al-Rawithi, S. Al-Gazlan, W. Al-Ahmadi, I. Alshowaier, A.Yusuf, D. Raines, A, "Expedient Liquid Chromatographic Method with Fluorescence Detection for Montelukast Sodium in Micro-Samples of Plasma," Journal of Chromatography B, Biomedical Sciences and Applications, vol. 754, no. 2, pp. 527-531, 2001.

[27]. H. Ochiai, N. Uchiyama, T. Takano, K. Harsa, T. Kamei, "Determination of Montelukast Sodium in Human Plasma by Column-Switching High Performance Liquid Chromatography with Fluorescence Detection," Journal of Chromatography B, vol. 713, no. 2, pp. 409-414, 1998.

[28]. B. Chauhan, R. Shubha, M. Nivsarkar, H. Padh, "A New Liquid-Liquid Extraction Method for Determination of Montelukast in Small Volume Human Plasma Samples using HPLC with Fluorescence Detector," Indian Journal of Pharmaceutical Sciences, vol. 68, no. 4, pp. 517-520, 2006.

[29]. L. Liu, H. Cheng, J. J. Zhao, J. D. Rogers, "Determination of Montelukast(MK-0476) and S-Enantiomer in Human Plasma by Stereo Selective High Performance Liquid Chromatography with Column Switching," Journal of Pharmaceutical and Biomedical Analysis, vol. 15, no. 5, pp. 631-638, 1997.

[30]. R. Papp, P. Luk, W. M. Mullett, E. Kwong, "A Rapid and Sensitive Method for Quantitation of Montelukast in Sheep Plasma using Liquid Chromatography/Tandem Mass Spectrometry," Journal of Chromatography B, vol. 858, no. 1-2, pp. 282-286, 2007.

[31]. D. V. Bharathi, K. K. Hotha, B. Jagadeesh, R. Mullangi, A. Naidu, "Quantification of Montelukast, A Selective Cysteinyl Leukotriene Receptor (Cyslt1) Antagonist in Human Plasma by Liquid Chromatography-Mass Spectrometry: Validation and its Application to A Human Pharmacokinetic Study," Biomedical Chromatography, vol. 23 , no. 8, pp. 804-810, 2009.

[32]. I. Alsarra, "Development of A Stability Indicating HPLC Method for the Determination of Montelukast in Tablets and Human Plasma and its Application to Pharmacokinetic and Stability Studies," Saudi Pharmaceutical Journal, vol. 12, no. 4, pp. 136-143, 2004.

[33]. B. E. Ahmed, A. S. Abdalla, Maha El-Tohamy, "Development and Validation of A HPLC Method for the Determination of Montelukast and its Degradation Products in Pharmaceutical Formulation using An Experimental Design,” Acta Pharmaceutica Sciencia, vol. 53, pp. 45-56, 2011.

[34]. International Conference on Harmonization (ICH Q2 (R1). Validation of Analytical Procedures: Text and Methodology, IFPMA, Geneva, Switzerland, 2005. 